\title{
Dose and temperature distribution in spent fuel containing material
}

\author{
Ladislav Viererbl ${ }^{1,}{ }^{*}$, Zdena Lahodová ${ }^{1}$, Jelena Zmítková ${ }^{1}$, Miroslav Vinš ${ }^{1}$, and Jiří Šrank ${ }^{2}$ \\ ${ }^{1}$ Research Centre Řě̌, Ltd., Hlavní 130, 25068 Řež near Prague, Czech Republic \\ 2 ÚJV Řež, a.s., Hlavní 130, 25068 Řež near Prague, Czech Republic
}

Received: 13 October 2015 / Accepted: 31 May 2016

\begin{abstract}
Spent fuel containing material (SFCM) can arise during severe nuclear reactor accident by melting of a reactor core and surrounding material (corium) or during accident in spent fuel storage. It consists of nuclear fuel, fission products, activation products and materials from fuel cladding, concrete, etc. The paper deals with dose and temperature characteristics inside the SFCM after transition of the molten mixture to solid state. Calculations were made on simplified spherical models, without connection to some specific nuclear accident. The dose rate was estimated for alpha, beta and gamma radiation in times over the course of 30 years from the end of the fission chain reaction. Concentration of helium generated in the material by alpha decay was calculated. For the dose rate values estimation, computation code ORIGEN 2.2 with dosimetric library ENDF/B-IV were used. Temperature distribution inside the solid SFCM was calculated by FLUENT code. As source of heating, energy of radioactive decays was taken. Estimated dose and temperature characteristics can be used, e.g. for evaluation of radiation damage and temperature behaviour of SFCM or for radiation test design of corium simulating materials.
\end{abstract}

\section{Introduction}

Spent fuel containing material (SFCM) can arise during severe nuclear reactor accident by melting of a reactor core and surrounding material (it is called corium in this case) or during accident in spent fuel storage. It consists of nuclear fuel, fission products, activation products and materials from fuel control rods, fuel cladding, concrete and other structural material [1]. Other compounds arise from products of their chemical reaction with air and water. The molten reactor core can release volatile elements and compounds. After a reactor or spent fuel storage accident, SFCM remains in a molten phase for some time, mainly due to fission products decay heating. When this heating decreases and/or cooling is applied, the SFCM changes to a solid state. The composition of SFCM at the time of solidification depends on reactor type, the nature of the accident, and many other factors.

This paper deals with dose characteristics inside the SFCM after transition of the molten mixture to a solid state. For calculations, simplified models of SFCM were used. The purpose of the calculation is not to describe some specific nuclear accident but estimated dose and

\footnotetext{
* e-mail: ladislav.viererbl@cvrez.cz, vie@cvrez.cz
}

temperature characteristics can be used, e.g. for evaluation of radiation damage and temperature behaviour of SFCM or for radiation test design of corium simulating materials [2].

\section{Time dependence of dose rate and helium generation in SFCM}

\subsection{Calculation model}

In the real event, SFCM composition, shape and dimensions could vary from case to case. For time dependence of dose rate calculations, a simplified model with the following assumptions was used:

- the SFCM is homogenous;

- the dose is equal to the decay energy (without neutrinos) released in unit mass (more details in Sect. 3);

- the dose rate is produced by alpha, beta and gamma radiation (contributions for example from neutrons and fission fragments are neglected);

$-10 \%$ of SFCM mass is uranium with fission and activation products created during irradiation. Uranium enrichment was $4.5 \%$ before fission. The remaining $90 \%$ is some "passive" material, e.g. Fe, $\mathrm{SiO}_{2}$. For this part of the calculation, the precise content is not important; 
Table 1. The most active fission products and actinide radionuclides ordered by mass activity for a time of $10^{7} \mathrm{~s}$ (116 days) after end of chain fission in SFCM.

\begin{tabular}{|c|c|c|c|}
\hline \multicolumn{2}{|c|}{ Fission products } & \multicolumn{2}{|c|}{ Actinides } \\
\hline Nuclide & $\begin{array}{l}a \\
(\mathrm{~Bq} / \mathrm{kg})\end{array}$ & Nuclide & $\begin{array}{l}a \\
(\mathrm{~Bq} / \mathrm{kg})\end{array}$ \\
\hline${ }^{95} \mathrm{Nb}$ & $3.62 \mathrm{E}+12$ & ${ }^{241} \mathrm{Pu}$ & $4.20 \mathrm{E}+11$ \\
\hline${ }^{144} \mathrm{Pr}$ & $3.55 \mathrm{E}+12$ & ${ }^{242} \mathrm{Cm}$ & $7.99 \mathrm{E}+10$ \\
\hline${ }^{144} \mathrm{Ce}$ & $3.55 \mathrm{E}+12$ & ${ }^{244} \mathrm{Cm}$ & $1.38 \mathrm{E}+10$ \\
\hline${ }^{95} \mathrm{Zr}$ & $2.03 \mathrm{E}+12$ & ${ }^{238} \mathrm{Pu}$ & $1.35 \mathrm{E}+10$ \\
\hline${ }^{106} \mathrm{Rh}$ & $1.49 \mathrm{E}+12$ & ${ }^{240} \mathrm{Pu}$ & $1.72 \mathrm{E}+09$ \\
\hline${ }^{106} \mathrm{Ru}$ & $1.49 \mathrm{E}+12$ & ${ }^{239} \mathrm{Pu}$ & $1.30 \mathrm{E}+09$ \\
\hline${ }^{91} \mathrm{Y}$ & $1.37 \mathrm{E}+12$ & ${ }^{241} \mathrm{Am}$ & $6.13 \mathrm{E}+08$ \\
\hline${ }^{89} \mathrm{Sr}$ & $8.55 \mathrm{E}+11$ & ${ }^{243} \mathrm{Cm}$ & $7.94 \mathrm{E}+07$ \\
\hline${ }^{103} \mathrm{Ru}$ & $8.16 \mathrm{E}+11$ & ${ }^{239} \mathrm{~Np}$ & $7.21 \mathrm{E}+07$ \\
\hline${ }^{103 \mathrm{~m}} \mathrm{Rh}$ & $7.35 \mathrm{E}+11$ & ${ }^{242} \mathrm{Am}$ & $4.93 \mathrm{E}+07$ \\
\hline${ }^{134} \mathrm{Cs}$ & $6.26 \mathrm{E}+11$ & ${ }^{237} \mathrm{U}$ & $4.17 \mathrm{E}+07$ \\
\hline${ }^{141} \mathrm{Ce}$ & $6.00 \mathrm{E}+11$ & ${ }^{244} \mathrm{Am}$ & $8.56 \mathrm{E}+05$ \\
\hline${ }^{147} \mathrm{Pm}$ & $4.80 \mathrm{E}+11$ & ${ }^{244 m} \mathrm{Am}$ & $3.49 \mathrm{E}+05$ \\
\hline${ }^{137} \mathrm{Cs}$ & $4.04 \mathrm{E}+11$ & ${ }^{238} \mathrm{~Np}$ & $2.48 \mathrm{E}+05$ \\
\hline${ }^{90} \mathrm{Y}$ & $2.97 \mathrm{E}+11$ & & \\
\hline
\end{tabular}

- uranium was irradiated in four reactor cycles per year as follows: $25 \%$ of the uranium was irradiated with neutrons for one year, $25 \%$ for two years, $25 \%$ for three years and $25 \%$ for four years. This corresponds to a situation where every year $25 \%$ of the fuel is changed and the end of chain fission (time of accident) is end of a reactor cycle;

- neutron fluence and spectrum of irradiation agree with PWR type reactors.

Dose rate, dose and helium production values are given for $10 \%$ uranium content. For other content levels, the values can be simply recalculated because in this simplified model they are proportional to uranium content.

\subsection{Radionuclide activities}

For radionuclide activities estimation, computation code ORIGEN 2.2 [3] with dosimetric library ENDF/B-IV was used. ORIGEN is a computer code system for calculating the build-up, decay, and processing of radioactive materials. ORIGEN 2.2 is a revised version that incorporates updates of reactor models, cross-sections, fission product yields, and decay data. This, not the newest version, was chosen for his simplicity of result outputs and sufficient precision for the given estimation.

Calculations were performed for 23 time points from 0 to $10^{9} \mathrm{~s}$ (32 years) after end of chain fission. Activities for about 1000 fission product radionuclides and 100 actinide radionuclides were calculated using the assumptions in Section 2.1. As an example, Table 1 provides a list of more important radionuclides in SFCM.

\subsection{Dose rate}

For dose rate calculations, 89 fission products and 17 actinide radionuclides were chosen. The selection was made according to activities at different time points. Radionuclides (elements) with a boiling point of less than $200{ }^{\circ} \mathrm{C}$ were not used due to supposed evaporation.

For selected radionuclides, energy released per decay was determined as the sum of products of Energy $x$ Intensity of the lines for alpha, beta and/or gamma radiation (including X-radiation) using NuDat [4] and Nucleonica [5] databases. By multiplying by activity and summing over selected radionuclides, final dose rates were given (Fig. 1). Absorbed doses can be obtained by integration of dose rates. Doses were calculated from a time of $100 \mathrm{~s}$ after the end of chain fission (Fig. 2). From these values, doses for chosen time interval can be obtained. For example, the total absorbed dose from all radiation types from $10^{4} \mathrm{~s}$ to $10^{8} \mathrm{~s}$ (2.8 hours to 3.2 years) is equal to $1.5 \times 10^{8} \mathrm{~Gy}$.

\subsection{Helium production}

Similarly as for dose rates, helium production was calculated from the count rate of alpha particles generated in alpha decays of actinides. Alpha particles make consecutively helium atoms. The count rate has similar shape as alpha dose rate. Integral count of helium atoms generated in unit mass of SFCM is in Figure 3.

With similar calculation as for dose, e.g. from $10^{4} \mathrm{~s}$ to $10^{8} \mathrm{~s}$ number of helium atoms generated in $1 \mathrm{~kg}$ of SFCM would be $6 \times 10^{18}$ atoms $/ \mathrm{kg}$.

The total uncertainty of the calculated values of dose rates, doses and helium concentration was estimated to be from 10 to $30 \%$, depending on the type of radiation, quantity, etc.

\section{Spatial distribution of dose rate in SFCM}

\subsection{Calculation model}

In Section 2 it was assumed that the dose is equal to the decay energy released from a unit mass, i.e. released energy is in equilibrium with absorbed energy. In other words, it was assumed that the SFCM has infinite dimensions. This is quite true for the inner part of an object that is large in comparison with the particle range in the material. For alpha particles, the typical range is in tens of $\mu \mathrm{m}$ and for beta particle less than one cm in SFCM. For gamma radiation, the typical half-value shield thickness is a few $\mathrm{cm}$ depending on radiation energy and SFCM composition. Gamma radiation is then most interesting with regards to the spatial distribution of dose rate. To illustrate this complex aspect, a few simple model examples were calculated.

Simplified models with following the assumptions were used for the calculations:

(a) the SFCM is homogenous;

(b) $10 \%$ of the mass is uranium and the remaining $90 \%$ is $\mathrm{SiO}_{2}$

(c) a spherical shape;

(d) the dose rate is produced by a homogenous monoenergetic gamma radiation source. 


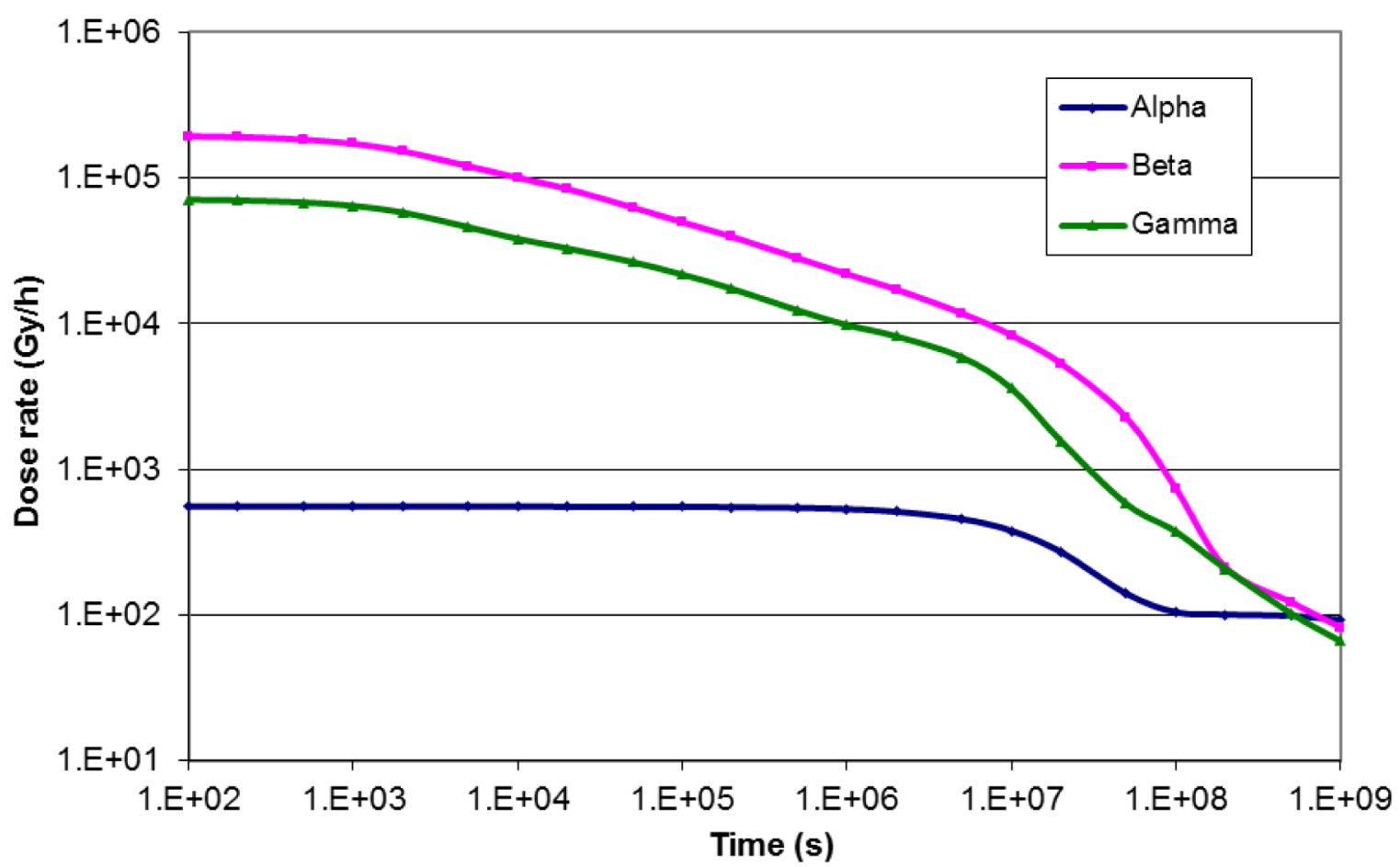

Fig. 1. Time dependences of dose rates for alpha, beta and gamma radiation in SFCM.

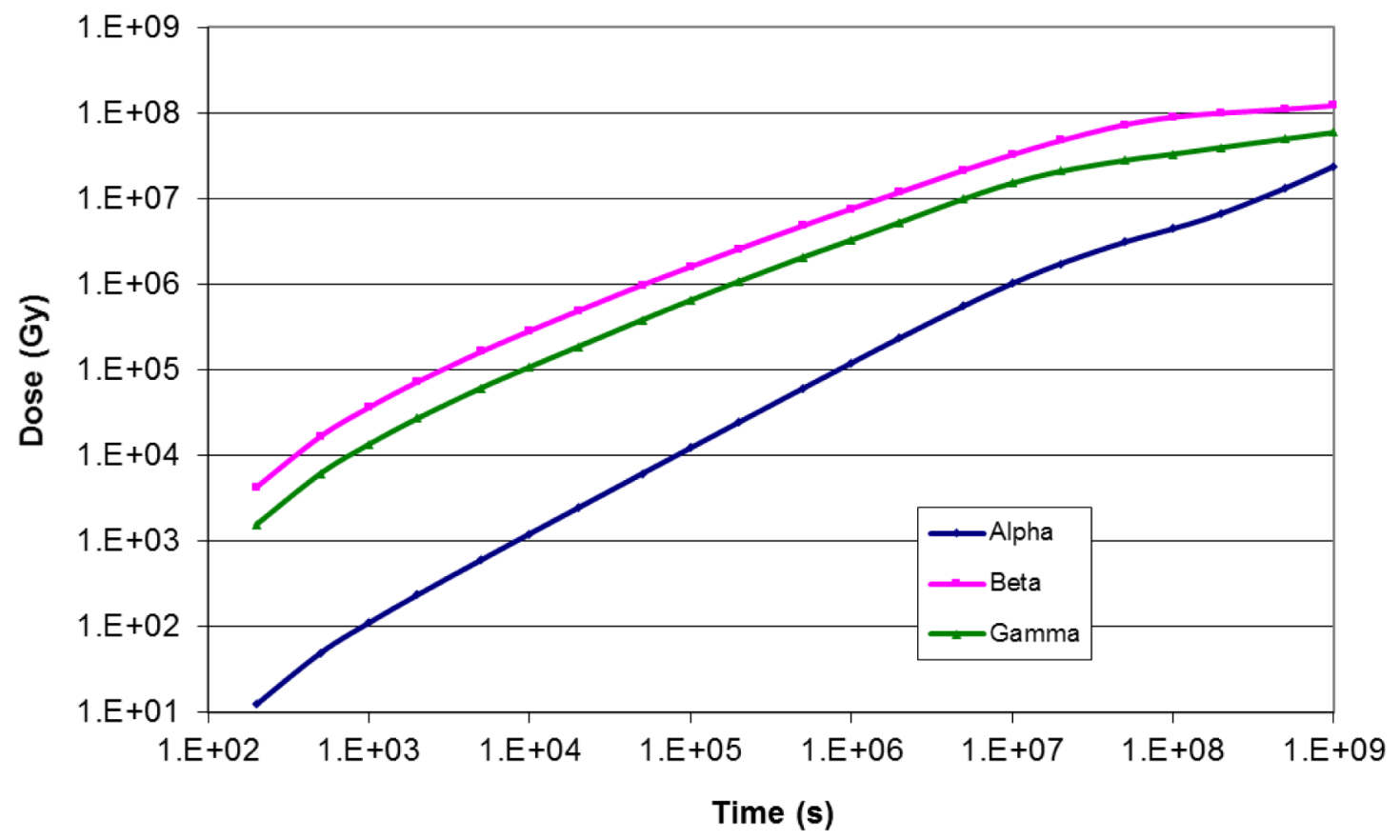

Fig. 2. Time dependences of doses in SFCM calculated from time of $100 \mathrm{~s}$ after the end of chain fission.

$\operatorname{MCNP}(\mathrm{X})$ [6] computer code with ENDF/B-VII.0 nuclear data library was used for calculation. The absorbed dose was computed using Type 3 mesh mode (energy absorption in volume) for spheres of diameters $6,10,30,60$, and $100 \mathrm{~cm}$. Source energies of $300 \mathrm{keV}, 661 \mathrm{keV}$, and $3000 \mathrm{keV}$ were also considered. These energies cover the possible range of emission energies of real isotopes.

\subsection{Results}

Spatial distributions of relative dose rates in SFCM for different energies and different diameters are shown in Figures 4 and 5. Relative values are normalized to released energy in a mass unit, i.e. $100 \%$ corresponds to values used in Section 2. 


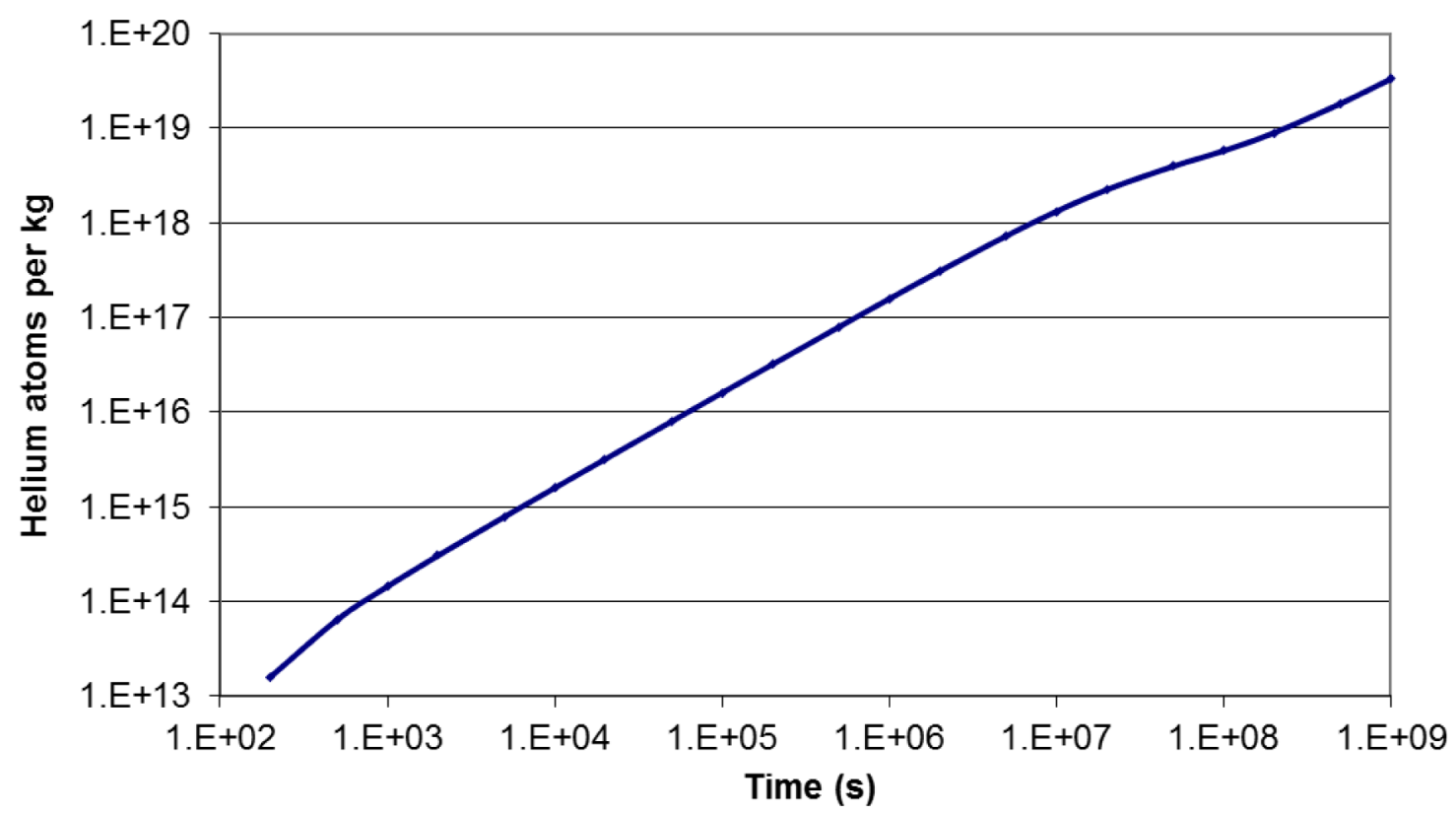

Fig. 3. Time dependence of helium atoms generated in SFCM from a time of $100 \mathrm{~s}$ after end of chain fission.

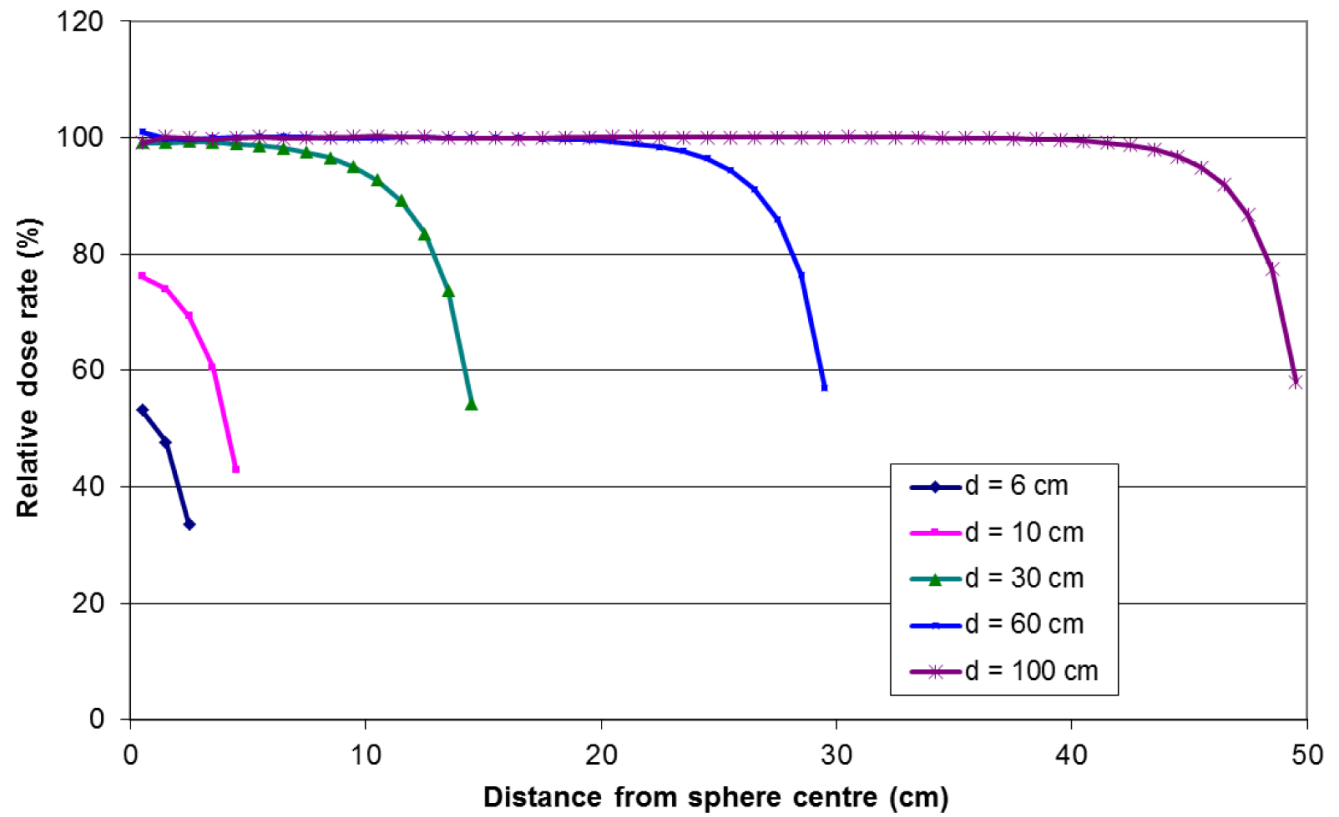

Fig. 4. Spatial distribution of relative dose rate for gamma energy of $300 \mathrm{keV}$ and different SFCM sphere diameters $d$.

The results confirm that assumption (b) in Section 2 (decay energy $=$ absorbed energy) is a good approximation for material dimensions above tens of centimetres even in case of high gamma energies. Uncertainty of the calculated values in this section for given assumptions was estimated to be $5 \%$.

\section{Temperature distribution in the SFCM}

\subsection{Calculation model}

To estimate the temperature field inside the SFCM, a simplified model was chosen with a homogenous spherical shape. The energy source was radiation heating taken from the dose rate calculation in Section 2. Perfect cooling was presumed on the sphere's surface. Geometry and calculation nets were created using GAMBIT 2.4.6 code, and thermal calculations were performed using ANSYS FLUENT 12 code [7] with some simplified assumptions.

A series of temperature distribution calculations in the SFCM sphere was performed, where the four variable input parameters were sphere surface temperature $T_{\mathrm{S}}$, sphere radius $R$, specific heat $Q$, and SFCM material (the effect of spent fuel with radionuclides in the SFCM on thermal parameters was neglected). Table 2 shows the various parameter values considered. Specific heat values were derived from dose rates in the SFCM (see Sect. 2.2) at different times after the end of the fission chain reaction 


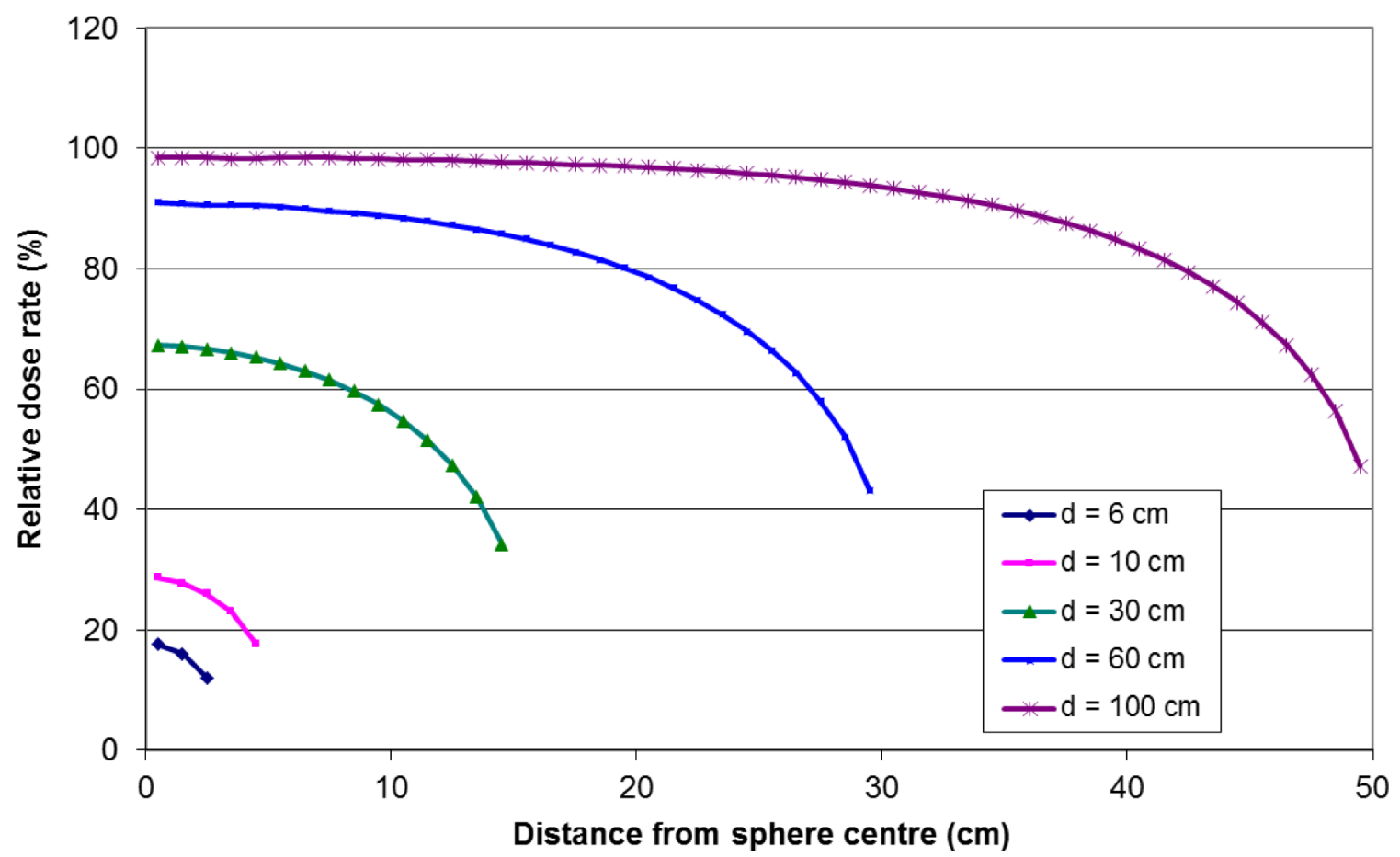

Fig. 5. Spatial distribution of relative dose rate for gamma energy of $3000 \mathrm{keV}$ and different SFCM sphere diameters $d$.

Table 2. Parameter variants for calculation.

\begin{tabular}{lllllll}
\hline$T_{\mathrm{S}}\left({ }^{\circ} \mathrm{C}\right)$ & $\mathbf{2 0}$ & 50 & 100 & 200 & 400 & 800 \\
$R(\mathrm{~cm})$ & 5 & 10 & 20 & $\mathbf{5 0}$ & 100 & 200 \\
$Q(\mathrm{~W} / \mathrm{kg})$ & 38.6 & 20.0 & 8.94 & $\mathbf{3 . 4 1}$ & 0.337 & 0.067 \\
Material & Steel & Concrete & Glass & $\mathbf{Z r O}_{2}$ & $\mathrm{ZrSiO}_{4}$ & $\mathrm{Al}_{2} \mathrm{O}_{3}$ \\
\hline
\end{tabular}

Table 3. Specific radiation heat versus times $t$ after the end of the fission chain reaction.

\begin{tabular}{lllllll}
\hline$t(\mathrm{~s})$ & $1.00 \mathrm{E}+04$ & $1.00 \mathrm{E}+05$ & $1.00 \mathrm{E}+06$ & $1.00 \mathrm{E}+07$ & $1.00 \mathrm{E}+08$ & $1.00 \mathrm{E}+09$ \\
$Q(\mathrm{~W} / \mathrm{kg})$ & 38.6 & 20.0 & 8.94 & 3.41 & 0.337 & 0.067 \\
\hline
\end{tabular}

(Tab. 3). Baseline values were chosen as follows (bold values in Tab. 2): $T_{\mathrm{S}}=20{ }^{\circ} \mathrm{C}, R=50 \mathrm{~cm}, Q=3.41 \mathrm{~W} / \mathrm{kg}$, and $\mathrm{ZrO}_{2}$ material. During each calculation, only one of the parameters was varied from baseline values.

\subsection{Results}

Figure 6 shows the calculated temperature distribution in the SFCM sphere for the baseline variant. Naturally, the distribution is spherically symmetrical with the maximum temperature $T_{\mathrm{C}}$ in the sphere's centre. The distribution shape is similar for different variants and varies mainly in the temperature difference $\Delta T$ between the sphere's centre and the sphere's surface, $\Delta T=T_{\mathrm{C}}-T_{\mathrm{S}}$. This value is therefore given as the only parameter characterizing the temperature distribution for a variant. Then, for example for the baseline variant with surface temperature $T_{\mathrm{S}}=20{ }^{\circ} \mathrm{C}$ and centre temperature
$T_{\mathrm{C}}=424{ }^{\circ} \mathrm{C}$, the difference $\Delta T=404 \mathrm{~K}$. For varying surface temperature $T_{\mathrm{S}}$, a constant difference $\Delta T$ is used for calculation approximation. Thus for example for $T_{\mathrm{S}}=120{ }^{\circ} \mathrm{C}$, we would have $T_{\mathrm{C}}=524^{\circ} \mathrm{C}(R, Q$ and material as in the baseline variant). For values of $\Delta T$ for varying $R, Q$, and material, see Tables 4-6. When temperatures obtained by simplifying formal calculations are above the material's melting point, the values are given in brackets.

\section{Discussion and conclusion}

The estimated calculation uncertainties in dosimetry parameters for spent fuel containing material (up to $30 \%$ in Sect. 2 and $5 \%$ in Sect. 3) are sufficient because uncertainties in composition and other SFCM parameters would in reality be much greater. Thermal calculations confirmed that due to radiation heating, temperature inside 


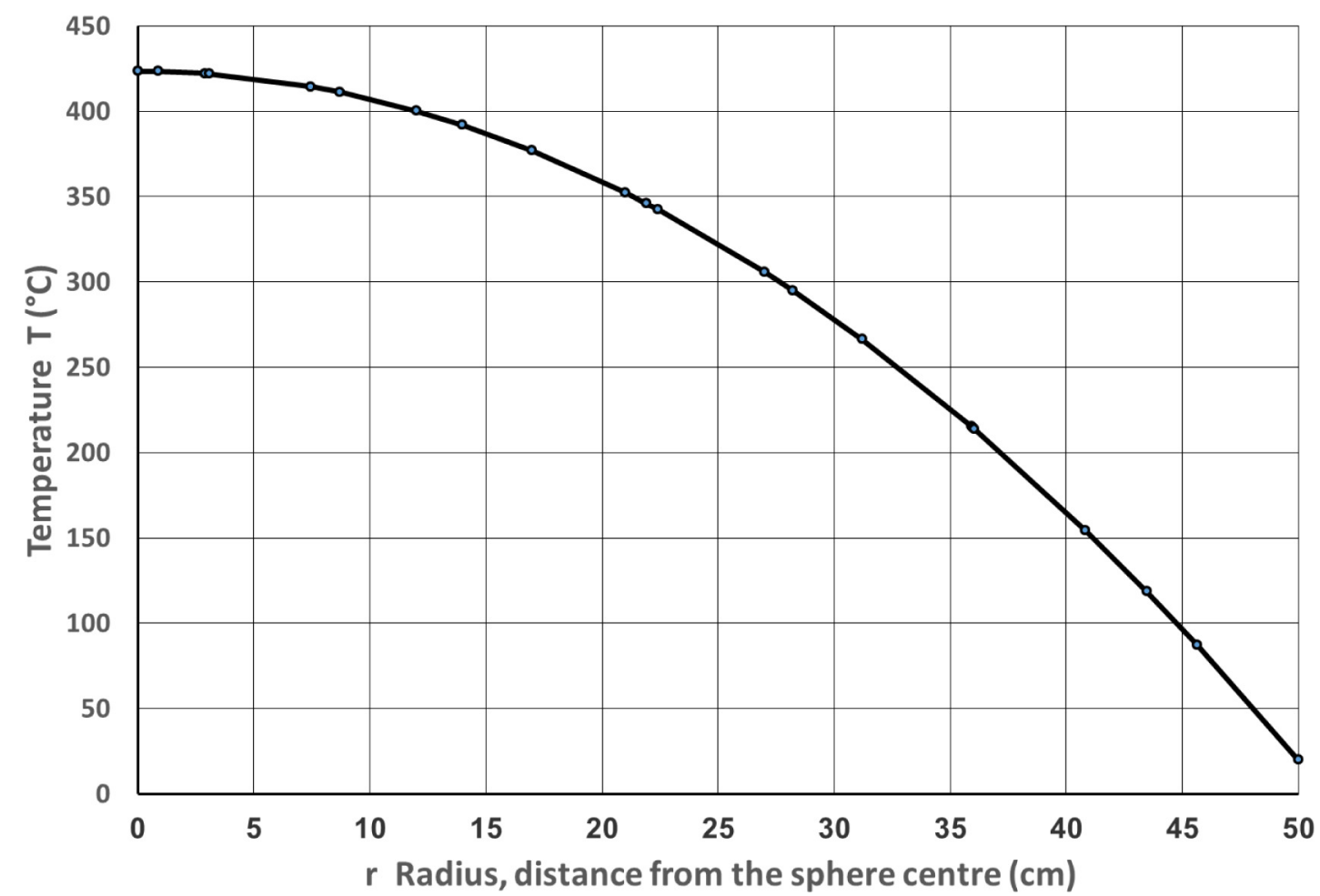

Fig. 6. Temperature distribution in the sphere for the baseline variant. $T_{\mathrm{S}}=20^{\circ} \mathrm{C}, R=50 \mathrm{~cm}, Q=3.41 \mathrm{~W} / \mathrm{kg}$ and $\mathrm{ZrO} 2 \mathrm{material}$.

Table 4. Temperature difference for varying sphere radius $R$.

\begin{tabular}{llllccl}
\hline$R(\mathrm{~cm})$ & 5 & 10 & 20 & 50 & 100 & 200 \\
$\Delta T(\mathrm{~K})$ & 4.0 & 16.1 & 64.6 & 403.5 & 1614.1 & $(6456.3)$ \\
\hline
\end{tabular}

Table 5. Temperature difference for varying specific heat $Q$.

\begin{tabular}{llrrrrl}
\hline$Q(\mathrm{~W} / \mathrm{kg})$ & 38.6 & 20.0 & 8.94 & 3.41 & 0.337 & 0.067 \\
$\Delta T(\mathrm{~K})$ & $(4567.7)$ & 2366.7 & 1057.9 & 403.5 & 39.9 & 7.9 \\
\hline
\end{tabular}

Table 6. Temperature difference for varying materials.

\begin{tabular}{lllllll}
\hline Material & Steel & Concrete & Glass & $\mathrm{ZrO}_{2}$ & $\mathrm{ZrSiO}_{4}$ & $\mathrm{Al}_{2} \mathrm{O}_{3}$ \\
\hline$\Delta T(\mathrm{~K})$ & 21.9 & 163.4 & 492.7 & 403.5 & 121.5 & 18.9 \\
\hline
\end{tabular}

a larger SFCM volume may reach relatively high values even if the SFCM surface is cooled intensively. These results can help to explain corium behaviour during cooling.

Estimated absorbed dose characteristics can be used to evaluate radiation damage and temperature behaviour of SFCM. These dose values can be also used for radiation test design of corium simulating materials. The typical total dose absorbed in the material over a few years after the end of chain fission was estimated on the order of $10^{8}$ Gy. This dose can be achieved with irradiation in a middle power research reactor over 1-100 days, depending on proximity to the reactor core and other irradiation conditions. The results were used for radiation tests design with corium simulating materials, which were made in LVR-15 research reactor and which are described in reference [2].

This work was performed within the scope of research project LH12224, KONTAKT II, the Ministry of Education, Youth and Sports.

\section{References}

1. C. Journeau, P. Piluso, K.N. Frolov, Corium physical properties for severe accident, R\&D, in Proceedings of ICAPP'04, Pittsburgh, PA, USA, June 13-17, 2004 (2004), Paper 4140

2. Z. Lahodová, L. Viererbl, M. Vinš, A. Voljanskij, M. Kiselová, Irradiation of materials intended for chemical and thermal stabilization of molten nuclear fuel, in TopFuel 2015 Conference, Zurich, Switzerland, September 13-17, 2015 (2015)

3. ORIGEN 2.2, RSICC Computer Code Collection, Oak Ridge National Laboratory, 2002

4. NuDat, National Nuclear Data Centre, 1997

5. Nucleonica GmbH, Nucleonica Nuclear Science Portal (www.nucleonica.com), Version 3.0.11, Karlsruhe, 2014

6. MCNPX user manual, Version 2.7.0, LA-CP-11-00438, 2011

7. ANSYS FLUENT 12.0 Theory Guide, ANSYS, Inc., 2009

Cite this article as: Ladislav Viererbl, Zdena Lahodová, Jelena Zmítková, Miroslav Vinš, Jiří Šrank, Dose and temperature distribution in spent fuel containing material, EPJ Nuclear Sci. Technol. 2, 31 (2016) 